\title{
VERTICALIZAÇÃO E COMPETITIVIDADE NA CADEIA DE SUPRIMENTOS DO SETOR DE APARELHOS CELULARES NO BRASIL: um estudo comparativo entre Motorola e Gradiente
}

\section{1- Fabio Castanheira}

Mestrado Profissional em Administração pela Fundação Getúlio Vargas (EAESP/FGV)

fabio.castanheira@uol.com.br

\section{2- Luiz Carlos Di Serio}

Doutorado em Engenharia Mecânica pela Universidade de São Paulo (USP)

Professor na Fundação Getúlio Vargas (EAESP/FGV)

Idiserio@fgvsp.br

http://lattes.cnpq.br/9361065863868373

\section{3- Gilnei Luiz de Moura*}

Doutorado em Administração pela Universidade de São Paulo (USP)

Professor na Universidade Federal de Santa Maria (UFSM)

mr.gmoura@smail.ufsm.br

http://lattes.cnpq.br/6056533356349635

\section{4- Guilherme Silveira Martins}

Doutorando em Administração pela Fundação Getulio Vargas (EAESP/FGV)

mr.gsmartins@gmail.com

http://lattes.cnpq.br/3674549394757140 
VERTICALIZAÇÃO E COMPETITIVIDADE NA CADEIA DE SUPRIMENTOS DO SETOR DE APARELHOS CELULARES NO BRASIL: UM ESTUDO COMPARATIVO ENTRE MOTOROLA E GRADIENTE

\title{
RESUMO
}

A dinâmica da cadeia de telefones celulares tem se modificado nos últimos anos, no sentido de formação de estruturas cada vez mais desverticalizadas. Tal fenômeno pode vir a mudar toda cadeia de valor num futuro próximo, favorecendo a entrada de novas empresas, ao mesmo tempo em que coloca novos desafios aos tradicionais participantes do setor. Este trabalho procura identificar as relações causais entre verticalização e competitividade para a cadeia de aparelhos celulares no Brasil. Para tanto, foram analisados dois casos contrastantes: o caso da Motorola, com modelo tradicional - verticalizado; e o caso da Gradiente, com modelo inovador em sua concepção da cadeia de valor - desverticalizado. A coleta de dados foi extensa, incluindo entrevistas com representantes-chave da indústria, questionários estruturados, análise documental e observação participante. Algumas das evidências encontradas foram à contínua modularização das arquiteturas de produto, a baixa especificidade dos ativos, as possibilidades de compra de escala de terceiros, a diminuição dos custos de coordenação, o surgimento de players de nicho, a stagnização de uma grande parte dos segmentos de mercado, as baixas barreiras de entrada para novos competidores e os poderosos compradores que têm interesse no fomento de novos fornecedores.

Palavras-Chave

Estratégia; Verticalização; Competitividade; Cadeia de suprimentos; Indústria de telefones celulares.

VERTICAL INTEGRATION AND COMPETITIVENESS IN INDUSTRY OF MOBILE PHONES SUPPLY CHAIN IN BRAZIL: A COMPARATIVE STUDY BETWEEN MOTOROLA AND GRADIENT

\begin{abstract}
The dynamics of cellular phones chain have been modified in recent years, with formations of structures increasingly more verticals disintegration. This phenomenon might change the whole value chain in the near future, encouraging the entry of new players, in the same time that put new challenges for traditional industry participants. This study aims to identify causal relationships between vertical integration and competitiveness for the cellular phones chain in Brazil. For this were analyzed two contrasting cases: the case of Motorola, with the traditional model - vertical, and the case of Gradient, with innovative design in its conception of the value chain - vertical disintegration. The data collection was extensive, including interviews with key representatives from industry, structured questionnaires, documentary analysis and participant observation. Were found some evidences: (1) a continuous modularization of product architectures; (2) low asset specificity; (3) the possibility of purchasing third-party scale; (4) decreasing costs of coordination; (5) the emergence of niche players; (6) the commoditization of many of the segments market; (7) low barriers to entry for new competitors; and (8) the buyers who have strong interest in developing new suppliers.
\end{abstract}

\section{Keywords}

Strategy; Vertical Integration; Competitiveness; Supply Chain; Industry of Mobile Phones. 


\section{Introdução}

A indústria de aparelhos de telefones celulares experimentou altas taxas de crescimento em todo o mundo, desde o seu lançamento há pouco mais de 20 anos. Em 2007, mais de três bilhões de usuários possuíam aparelhos celulares no mundo, i.e., um aparelho para cada dois habitantes do planeta, número bem superior aos de telefonia fixa, da televisão, da internet e do próprio rádio.

O produto, que revolucionou as comunicações modernas, não evoluiu apenas em números. Conforme comenta Christensen (2003), no início eram volumosos aparelhos para serem utilizados em automóveis, que consumiam muita energia e tinham eficácia apenas local. O avanço da tecnologia proporcionou muitas melhorias na concepção do produto, com a adição de uma série de facilidades no aparelho. A corrida que se deflagrou por penetração de mercado, fez com que os custos iniciais para compra de um aparelho passassem de US\$ 4.000 em 1983 para US\$30 em 2007.

Porter (1980), Christensen (2003) e Fine (2000) reconhecem que a indústria e os mercados evoluem, criando novas regras, cujos diferentes modelos de negócio das empresas são mais ou menos adequados, em função da sua efetividade em capturar oportunidades e mitigar ameaças. No caso da cadeia de aparelhos para telefonia celular, é passível de se afirmar que a velocidade com que as mudanças do ambiente ocorrem seja mais acentuada.

Num ambiente tão dinâmico, os pontos da cadeia que geram valor estão em constante mudança. Por essa razão as empresas devem dar atenção ao projeto da empresa ampliada, aqui definida como a empresa em si, acrescida de sua rede de fornecimento, de sua rede de distribuição, e de sua rede de alianças (FINE, 2000).

A discussão sobre fazer ou comprar (make-or-buy) têm aplicação direta e constante nas cadeias de suprimento, especialmente naquelas em que se observa maior velocidade evolutiva. Fine (2000) vê os graus de verticalização como um ciclo infinito, onde as empresas de uma determinada indústria, pressionadas por forças internas e externas, alternam no tempo entre estruturas verticalizadas ou desverticalizadas.

O tema "o que fazer", "o que comprar" foi norteador de muitos estudos, como os de Hamel e Prahalad (1994), Quinn e Hilmer (1994), Venkatesan (1992) e Di Serio e Sampaio (2001), entre outros. Estes estudos concentraram-se em avaliar prós e contras do processo de terceirização para uma entidade específica. São modelos que orientam a organização a selecionar e desenvolver internamente somente as competências de maior valor agregado para os clientes, almejando, assim, conquistar uma vantagem competitiva sustentável.

Particularmente, a indústria automobilística e a de eletro-eletrônico são objetos de estudos sobre verticalização, pois possuem alguns aspectos em comum como (i) produtos modularizados, com arquitetura predominantemente montada a partir de componentes básicos produzidos por fornecedores; (ii) estes fornecedores estão em número expressivo e são pequenas e médias empresas; e (iii) número reduzido de empresas montadoras do produto final (Cañez; Probert \& Plattz, 2000).

Dado o exposto, pretende-se neste trabalho analisar a dinâmica de verticalização e a competitividade das estratégias em operações da cadeia de fabricantes aparelhos celulares no Brasil. Para tanto, foram selecionados duas empresas com configurações cadeias de suprimentos bem distintas: um por representar um modelo de negócio tradicional e integrado (Motorola) e outro por ser um modelo de negócio inovador, desverticalizado (Gradiente). Esta escolha foi intencional, por se saber, a priori, que os dois modelos de negócio representados eram antagônicos no que diz respeito às variáveis dependentes escolhidas (verticalização e estratégias em operações).

Este trabalho tem a virtude de acrescentar conhecimento específico à área da indústria de aparelhos celulares, que é ainda pouco estudada dentro da Administração. Em termos gerais pôde-se constatar primeiramente que a verticalização e as estratégias em operações podem gerar modelos de negócio mais ou menos eficientes e competitivos, pelo fato de os mesmos privilegiam aspectos mais adequados às regras de mercado vigentes num dado momento. Em seguida verificou-se uma sinalização de que a cadeia de aparelhos celulares no Brasil está chegando a um ponto de disruptura, onde modelos novos e desverticalizados podem vir a ganhar importância no mercado.

Para atingir o objetivo supracitado, o artigo está estruturado em cinco seções, incluindo esta parte introdutória. A segunda seção apresenta os conceitos de Dinâmica de Cadeias - Horizontalização / Verticalização - e de Competitividade em Operações - custo, qualidade, tempo, flexibilidade. A terceira 
expõe o método adotado para a realização desse trabalho. A quarta seção faz a apresentação e a discussão dos resultados da pesquisa por três diferentes ângulos: a Cadeia de Aparelhos Celulares no Brasil, a Cadeia da Gradiente e a Cadeia da Motorola. A quinta mostra os resultados comparados dos casos apresentados na seção anterior. A última seção relata as considerações finais, conclusões, limitações do estudo e sugestões de estudos futuros.

\section{Referencial Teórico}

\subsection{Dinâmica das Cadeias}

Fine $(1999,2000)$ preconiza que para entender a evolução, mutação, sobrevivência ou extinção de empresas é preciso estudar a dinâmica das cadeias. Desta forma, propõe um modelo de hélice dupla análoga a estrutura do DNA humano - em que o movimento do mundo empresarial é representado por um modelo com base em um ciclo duplo infinito, que se movimenta entre setores integrados verticalmente organizações complexas com atividades complementares - e setores desintegrados horizontalmente organizações com papéis bem definidos e restritos em elos da cadeia. A verticalização e a horizontalização da produção são processos dinâmicos, em que as forças competitivas integram e desintegram empresas e setores, conforme apresentado na figura 1.

Figura 1: modelo da hélice dupla

Fonte: adaptado de Fine (1999)

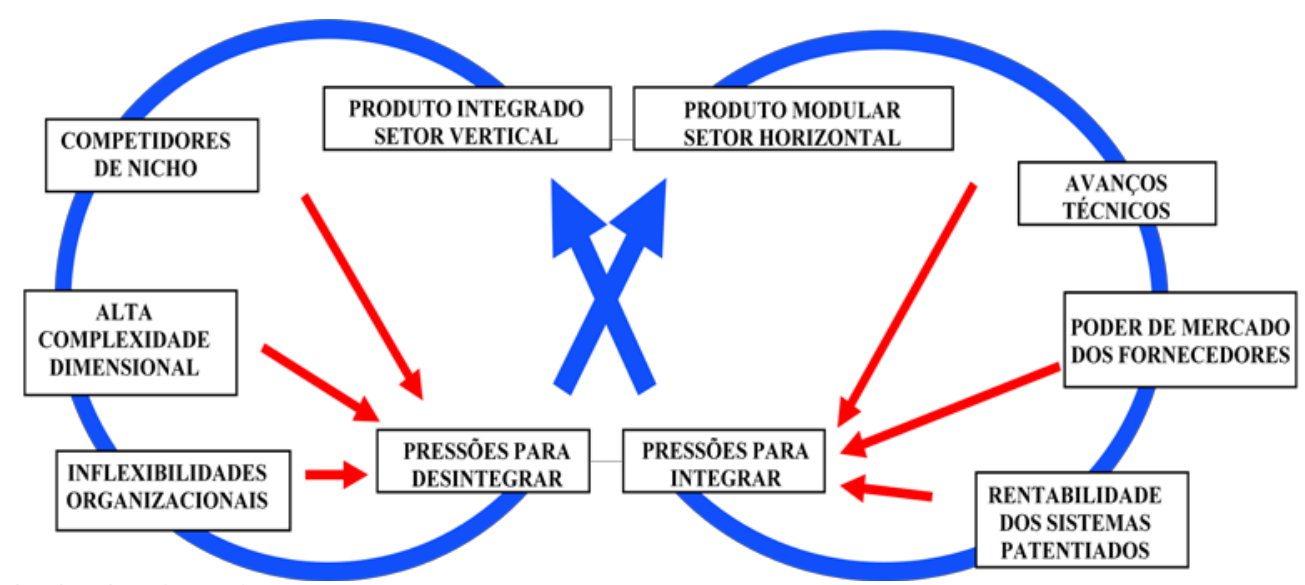

Fine (1999) descreve as forças da hélice dupla que atuam na desintegração da cadeia (configuração horizontal e modular) e as forças que atuam na integração da cadeia (arquitetura vertical e integrada). As forças de desintegração são: (i) entrada agressiva de competidores de nicho; (ii) o desafio de manter-se à frente da competição nas dimensões da tecnologia e do mercado; e (iii) a falta de flexibilidade da burocracia organizacional. Por sua vez, as forcas de integração se configuram como: (i) avanços técnicos; (ii) o poder do bundling (pacote de produtos); e (iii) a integração da engenharia dos subsistemas para desenvolver soluções patenteadas.

Fine (1999) define o conceito de produto com arquitetura modular ou integral. Para a arquitetura de processos, utiliza apenas duas dimensões - tempo e espaço -, devendo existir um processo contínuo de reavaliação dos elos estratégicos, por causa das pressões constantes para verticalizar/horizontalizar. Não existem vantagens competitivas permanentes, apenas vantagens temporárias em elos diferentes da cadeia ao longo do tempo. A velocidade de migração destas vantagens pela cadeia será dada pela dinâmica da indústria.

O desenvolvimento do produto envolve atividades de escolhas de arquitetura (modular ou integral) e de escolhas de projeto que estão relacionadas às funcionalidades dos mesmos e ao seu desempenho. Enquanto o desenvolvimento do processo está dividido em desenvolvimento de processos específicos que se referem à tecnologia e aos equipamentos necessários à produção e em desenvolvimento de sistemas de fabricação e operacionais. Por sua vez o desenvolvimento da cadeia de suprimentos envolve decisões sobre a sua arquitetura (integrada ou modular) e sobre o sistema de logística/coordenação. 
A teoria de Fine (1999), juntamente com a de Christensen (2003), baseia-se nos conceitos de modularidade de produto, exaustivamente investigados e propostos por Baldwin e Clark (1997). Consideram que, em arquiteturas modulares, pode-se integrar um número grande de fornecedores trabalhando sob um mesmo projeto sem que isso impacte na qualidade do produto acabado ou na eficiência da operação. Em seus postulados afirmam que a forma modular de produto permite às empresas lidar com um nível de complexidade tecnológica crescente.

Christensen (2003) relaciona o produto das empresas com aquilo que denomina "tarefa a ser executada". Isto significa que os clientes precisam que certas "tarefas" sejam realizadas com a regularidade desejada e para que isso aconteça, os mesmos procuram produtos e serviços oferecidos pelas empresas. Pelo conceito da tarefa executada criam-se duas circunstâncias distintas. A primeira quando o produto "não é bastante bom" para realizar a tarefa e a segunda quando o produto "é mais do que bastante bom". Quando o produto não é bastante bom cria-se uma lacuna de desempenho, que é o gap entre o que o cliente espera do produto e o que ele é capaz de executar.

Christensen (2003) defende que, quando existe essa lacuna uma arquitetura integrada é sempre melhor, pois privilegia desempenho em detrimento de flexibilidade. Por esse motivo as empresas que competem com arquiteturas integradas e interdependentes, portanto, devem ser verticalizadas. Pois, precisam controlar o projeto e a fabricação de todos os componentes críticos do sistema.

Ocorre que esse processo se transforma numa corrida pelo aperfeiçoamento dos produtos, acarretando que as melhores empresas expulsam seus adversários mais fracos e fortalecem crescentemente a sua estratégia de verticalização, até o ponto onde os produtos se tornam mais do que bastante bons. Nesse momento, uma boa parte do mercado não está disposta a pagar pelos custos excedentes da melhoria tecnológica oferecida e assim se cria o ambiente para que arquiteturas modulares entrem no mercado.

Evoluindo, o produto tende a se comoditizar com a entrada de empresas desverticalizadas no mercado, que por serem mais ágeis e flexíveis possuem custos mais baixos e atendem melhor os consumidores, mesmo com níveis de qualidade e desempenho inferiores. Num passo seguinte, o que se vê após a comoditização e a fragmentação da indústria, é que, em algum ponto, da cadeia fragmentada ocorre o processo de descomoditização (Christensen, 2003).

De várias formas as abordagens de Fine (1999) e Christensen (2003) apresentam similaridades: (i) ambos fazem uso das arquiteturas de produto para descreverem seus ciclos de oscilação entre verticalização e desverticalização; (ii) no modelo da hélice dupla, não fica tão claro como empresas de nicho irão conseguir aderir ao mercado, mas na disrupção isso fica muito claro, de forma que ambas as teorias estão alinhadas nesse sentido; (iii) os dois autores reconhecem que empresas que atingem seu apogeu ficam lentas e ineficientes, e por, isso passam a ser vítimas de modelos de negócio disruptivos. na velocidade evolutiva (Fine, 1999), entretanto isso fica mais explicitado; e (iv) ambos modelos alteram a especificidade do ativo, a escala de produção das empresas e a escala das transações, conduzindo a uma mudança significativa das variáveis de eficiência técnica e de eficiência de agência, explicando, da mesma forma, as ondas de verticalização e desverticalização que podem ser verificadas nas indústrias.

Além do mapeamento da cadeia de valor das empresas estudadas, faz-se necessário um estudo das cadeias de fornecedores da indústria. Neste sentido, a inovação tecnológica e o aumento da competição nos mercados têm provocado choques sobre o ambiente empresarial, econômicos, tecnológicos, de produtos e serviços revolucionários dos concorrentes e de modelos inovadores de negócio de empresas predominantes. Tal evento torna as vantagens competitivas temporárias, sendo que a chave para a sobrevivência consiste na adaptação. Por essa razão as empresas devem dar atenção ao projeto de uma empresa ampliada, acrescida de sua rede de fornecimento, de sua rede de distribuição, e de sua rede de alianças. Ressalta-se que a cadeia de fornecedores deve ser encarada como a montagem da "cadeia de capacidades". (Fine, 1999)

O planejamento de toda rede da cadeia de valor da empresa (cadeia de fornecimento) - sobretudo quais capacidades investir e quais terceirizar - é a competência mais importante no arsenal da empresa. Para isso, a construção de um mapeamento em três níveis da empresa: (i) a "cadeia da empresa"; (ii) a "cadeia de fornecimento de tecnologia"; e (iii) a "cadeia de capacidades". (Fine, 1999)

Fine (1999) sugere que a análise seja enriquecida com a formulação de um conjunto de perguntas simples para cada elemento de cada nível do mapa: (1) Qual a velocidade evolutiva desse elemento da cadeia e do setor em que está inserido? (2) Que fatores (por exemplo, aumento da competição a partir de novos entrantes, inovações tecnológicas no setor, nova regulamentação e outros) estão impulsionando a 
velocidade evolutiva desse elemento? (3) Quais as perspectivas de mudança na velocidade evolutiva desse elemento da cadeia como resultado das mudanças esperadas na intensidade competitiva ou no ritmo da inovação? (4) Onde o seu setor se localiza na hélice dupla? Ou seja, o setor se encontra, basicamente, numa fase de estrutura horizontal com produtos modulares, ou numa fase de estrutura vertical, com produtos altamente integrados? e (5) Qual a atual dinâmica de poder desse elemento da cadeia?

No campo de Economia, Willianson (1985) organizou que influenciam a verticalização da indústria numa metodologia muito elucidadora, a partir de dois conceitos - o de eficiência técnica e o de eficiência de agência - criou um balanço entre variáveis tangíveis e intangíveis, num equilíbrio que denominou de "Economizing". Ou seja, o ato de atingir uma estrutura otimizada face às decisões sobre verticalização contemplando os dois tipos de eficiência.

A eficiência técnica nada mais é do que a utilização da estrutura vertical que gera o processo de produção menos custoso (medida objetiva). Trata-se, portanto, do processo de produção. A eficiência de agência, por outro lado, diz respeito aos custos de transação e, portanto, ao processo de troca. Nele se incluem os custos de coordenação, de agência e de vazamento de informações que são fonte de vantagem competitiva para a empresa.

Na medida em que o mercado é sempre melhor para minimizar custos de produção e que estruturas verticais são superiores para minimizar custos de transação, os trade-offs entre esses dois custos são inevitáveis. Williamson (1985) argumenta que a organização vertical otimizada é aquela que minimiza a soma das ineficiências técnicas e de agência. Ou seja, as empresas decidindo sobre fazer internamente ou comprar do mercado ao longo da cadeia vertical, estão minimizando a soma dos custos de produção e dos custos de transação.

\subsection{Competitividade em Operações}

A Estratégia de Operações é uma estratégia funcional e, portanto, deve promover sustentação à estratégia competitiva. Neste sentido, Hayes e Upton (1998) consideram a estratégia de operações como um conjunto de objetivos, políticas e restrições auto-impostas que conjuntamente descrevem como a organização se propõe a dirigir e desenvolver todos os recursos investidos nas operações, de forma a melhor executar (e possivelmente redefinir) sua missão.

Considerando que os elementos que compõem o sistema produtivo são concebidos para atingir determinados fins e realizar determinadas tarefas, estratégias competitivas diferentes poderão exigir configurações distintas do sistema de produção. Uma das vantagens na definição dos critérios competitivos é compreender seus reflexos nas decisões estruturais e táticas da organização (Wheelwright, 1984). Assim, cada tipo de estratégia demanda certas tarefas da produção e está relacionada a determinados objetivos, os quais são conhecidos por "prioridades competitivas" e foram inicialmente identificados por Skinner (1969) como sendo produtividade, serviço, qualidade e retorno sobre investimento.

Ao contrário do que se pensava no passado, onde 'operações' era apenas uma das dimensões de toda abrangência gerencial (as outras duas sendo estratégica e tática), atualmente o que se observa é que essa área pode ser efetivamente a fonte de vantagem competitiva da empresa e, portanto, consubstancia-se numa grande porção da estratégia propriamente dita.

Operações pode ser a estratégia principal da empresa rumo a dispor de vantagens competitivas mais efetivas do que as de seus concorrentes. As decisões de operações definem o modelo de negócio e as decisões sobre verticalizar ou fragmentar além da alocação dos recursos. De modo análogo, pode-se ser levado a acreditar que inovação seja um atributo de produto unicamente. Ocorre que as inovações de processo, ou de uma nova organização também são importantíssimas para se obter eficiência e competitividade.

De acordo com Besanko, Dranove, Shanley \& Schaefer (2004) para formular e implementar uma estratégia bem sucedida, uma empresa tem que se confrontar e tomar decisões sobre quatro classes abrangentes de questões, a saber: (i) Fronteiras da Empresa; (ii) Análise de Mercado e de Competitividade; (iii) Posicionamento e Dinâmica; e (iv) Organização Interna.

Recursos e capacidades são as verdadeiras fontes de vantagem competitiva para a empresa. Encontrar formas de fazer melhor do que a concorrência é como construir fortalezas que sustentarão grande parte do sucesso e do resultado da empresa. Neste sentido, as decisões de verticalização podem representar 
vantagens competitivas por se constituir em configurações mais eficientes de organização das atividades, face ao momento em que a indústria vive. Comprar insumos ou produzi-los internamente; ou vender para os seus clientes, ou possuir essa etapa da cadeia, são as decisões que têm que ser tomadas para se constituir a forma mais eficiente de se operar.

Resultante de duas forças, uma externa, dinâmica e incontrolável e outra interna representada pela formulação estratégica, baseada em recursos e decisões sobre verticalização, o modelo de negócio materializa e sintetiza todas as variáveis. Dos acertos aos erros, até às alterações causadas pelo ambiente, tudo pode ser visto no modelo de negócio. Os enfoques que se dão em cada área ou função são essenciais para se criar uma estratégia vencedora, de dentro para fora da empresa.

A 'cadeia de valor' (Porter, 1980) é um método que cumpre como função, auxiliar na compreensão, desenho e ajuste do modelo de negócio da empresa. Pode ser usado de forma comparativa para se entender as similaridades relevantes e as igualdades entre o modelo de negócio da empresa e de seus concorrentes.

Diante do contexto descrito, tem-se que o estudo do ambiente interno da empresa se faz primordial, uma vez que é pelo equacionamento dos recursos internos face às condicionantes externas, que as empresas desenvolvem suas vantagens competitivas. A teoria de Barney (1991) sobre recursos propõe um modelo para se identificar recursos que possam ser identificados como vantagens competitivas sustentáveis. Assim sendo, os recursos são definidos como tangíveis e intangíveis.

As capacidades são as habilidades de organizar os recursos intencionalmente predispostos de forma que uma condição final desejada seja atingida. Para Barney (1991) para um recurso ser fonte de vantagem competitiva sustentável deve atender a quatro condições simultaneamente: (i) ser valioso; (ii) ser raro; (iii) ser difícil de imitar; e (iv) ser insubstituível.

Por outro ponto de vista, Slack (2002) considera que os "consumidores" são os verdadeiros árbitros do mercado. São eles que definem quais metas de desempenho são mais ou menos importantes. Neste sentido, a função de manufatura têm cinco objetivos de desempenho: (i) custos; (ii) velocidade; (iii) confiabilidade; (iv) qualidade; e (v) flexibilidade. Por fim, a vantagem competitiva decorre de fazer as coisas melhor do que os concorrentes.

\section{Definições Metodológicas}

Este trabalho tem como propósito central entender se essas decisões de verticalização e as estratégias em operações criam diferenças em eficiência e competitividade nas empresas da cadeia de aparelho celulares no Brasil. Trata-se de um trabalho empírico que aprofunda a análise acerca das composições dessas variáveis e quais modelos seriam mais beneficiados. A situação enfrentada é única, sendo que o número de variáveis de interesse é muito maior do que os pontos de dados. Desta forma, dentre os propósitos de pesquisa elencados por Scapens (1990), este artigo enquadra-se como um estudo explanatório

Em termos específicos buscou-se (i) definir qual o momento atual da indústria de aparelhos celulares (Porter, 1980); (ii) procurar indícios sobre as forças que atuavam no mercado favorecendo, ou desfavorecendo a verticalização; e (iii) descrever o comportamento das forças desta indústria. (Porter, 1980)

O estudo em questão seguiu o paradigma fenomenológico (qualitativo), devido em grande parte à natureza do problema de pesquisa enfrentado, uma vez que, foram examinadas pequenas amostras, durante certo período de tempo, de um fenômeno que tem sido observado no cotidiano organizacional (Van Maanen, 1988). Em outras palavras, procurou-se entender elementos importantes em modelos de negócio diferentes. Tratou-se de situações únicas ligadas a um contexto particular e que deve ser executado por meio de verificação.

Os dados produzidos e posteriormente analisados foram qualitativos e quantitativos. A ênfase colocada foi na qualidade e na profundidade de dados dotados de pleno significado, já que captaram a riqueza de detalhes e as nuances dos fenômenos deste estudo. (Collis e Hussey, 2003). A generalização dos resultados foi possível por meio da identificação de padrões, conceitos e teorias, uma vez que se almejou captar as interações e características do fenômeno que se estava estudando (Normann, 1970). 
Dentro do paradigma fenomenológico, foi adotado o estudo de caso como metodologia de pesquisa. Para Yin (2005), a estratégia de estudo de caso faz parte de um grupo maior de outras estratégias que endereçam os problemas de pesquisa fenomenológica, a saber, experimento, levantamento, análise de arquivos e pesquisas históricas. Neste sentido, os três critérios para a escolha da estratégia seriam: a) a forma da questão de pesquisa; b) se a mesma exige controle sobre os eventos comportamentais e; c) se focaliza acontecimentos contemporâneos. Esta pesquisa focou-se nos 'comos' e 'porquês', até porque houve pouco controle sobre os acontecimentos (agente independente), pois se esteve lidando com dois casos específicos, que podem ser percebidos como um fenômeno contemporâneo. Sendo adotada a variante estudo de caso múltiplo.

Os casos selecionados foram dois modelos de negócio da indústria de celulares no Brasil intencionalmente escolhidos, pois apresentam situação de contraste no que se refere à sua estratégia operacional e às decisões de verticalização de seus modelos de negócio. Dessa forma, estará se falando de um "estudo comparado". Acredita-se que isto traga maior interesse ao artigo devido ao fato de que as evidências resultantes possam ser consideradas mais convincentes e o estudo global possa ser visto como mais robusto (Herriott e Firestone, 1983).

Para Yin (2005), qualquer estudo de caso múltiplo deve seguir uma lógica de replicação. Uma de suas vantagens é que o mesmo se apóia na lógica da replicação em uma figura análoga aos experimentos múltiplos. A lógica da replicação (assim como a de experimentos múltiplos) prevê que os casos são selecionados de forma a: (i) prever resultados semelhantes (uma replicação literal), ou; (ii) produzir resultados contrastantes apenas por razões previsíveis (uma replicação teórica). Desta forma, entende-se que foram escolhidos casos contrastantes, buscando-se observar uma replicação teórica e não linear.

\subsection{Coleta e Análise de Dados}

Uma das formas mais efetivas de se estabelecer a validade do constructo e a confiabilidade de um estudo de caso é o uso de varias fontes de evidência (Yin, 2005). Para tanto, foram utilizadas cinco fontes de dados principais nesta pesquisa: entrevistas preliminares, documentos; entrevistas; questionários e observação participante.

As entrevistas preliminares com três participantes (capacitados e formadores de opinião) de gerência média das empresas foi o recurso utilizado como primeiro passo na coleta de dados. O uso de documentos foi importante para corroborar e valorizar as evidências oriundas de outras fontes, principalmente na triangulação de informações obtidas de questionários e entrevistas. Isto foi muito relevante, no caso da Motorola, onde as informações públicas eram abundantes.

Uma das mais importantes fontes de informação para um estudo de caso são as entrevistas (Yin, 2005). Neste estudo, foram realizadas entrevistas com profissionais relevantes do mercado. Assim como sugerido em métodos fenomenológicos, as perguntas foram do tipo não-estruturadas ou semi-estruturadas. Os motivos levantados por para utilização desse método dão sustentação ao enquadramento da opção aqui adotada, i.e., esta opção é aconselhável quando o assunto é altamente confidencial ou comercialmente sensível (Easterby-Smith, Thorpe, \& Lowe, 1991).

O recurso questionário passou por um teste piloto. Os questionários adotados se distinguem pela linha teórica ou pela análise do setor ou por cada um dos casos estudados, Motorola e Gradiente. Utilizou-se como base inicial para o questionário estruturado de Estratégias Genéricas de Porter o trabalho de Guedes (2004) e para as cinco forças competitivas de Porter, o trabalho de Rebelo (2004). As questões, na maior parte das vezes, eram de múltipla escolha para facilitar a sua tabulação. Todos os questionários foram enumerados para ajudar na organização das informações.

Os questionários foram aplicados aos executivos de nível estratégico que se dispuseram a dedicar tempo a esse tema e às pessoas de nível mais operacional na organização, mas altamente recomendadas e preparadas para tratar com as questões pertinentes ao tema. Os pesquisadores decidiram por não se restringirem aos executivos dos dois casos pesquisados, pois o trabalho de propunha a discutir a dinâmica desta cadeia. Assim, tentou-se diversificar o público em termos de posicionamento do sistema de valor (Porter, 1980), tais como os principais operadores de serviço celular, alguns fabricantes (incluindo Motorola e Gradiente), distribuidores e desenvolvedores de produtos.

A observação participante foi propiciada, por um dos pesquisadores ser profissional de mercado, mais especificamente, no cargo de gerente geral para a operação de aparelhos celulares de um grande 
fabricante japonês, a Kyocera. Neste ambiente, este pesquisador se defrontou com os grandes desafios do setor e participou intensamente de decisões estratégicas que versavam especificamente sobre como competir com estratégias baseadas em novos modelos de negócios desverticalizados, na indústria.

A análise dos dados teve ênfase qualitativa e fez uso da técnica de análise de conteúdo proposta por Bardin (1977). O estudo foi realizado no ano de 2007.

\section{Apresentação e Discussão dos Resultados}

Há indícios de que a indústria de aparelhos celulares favorece o surgimento de negócios disruptivos, seja baseado em produtos provenientes de novas tecnologias, tais como os smartphones e PDA's mencionados acima, seja por que as empresas começam a fabricar, para uma grande parte do mercado, produtos mais sofisticados do que o ele necessita. Os dispositivos de mão são disrupções de novo mercado em relação aos computadores e notebooks, como Palm Pilot, R/Me BlackBerry (Christensen, 2003).

Em resumo, os resultados indicam que os custos de agência tendem a se agravar conforme as empresas crescem e ganham idade. O mesmo ocorre com os custos de influência. Já os custos de coordenação, quando a estrutura é fragmentada, têm caído assustadoramente em função do advento das comunicações em tempo real. Com a diminuição do ciclo de vida dos produtos e, portanto, do aumento da velocidade evolutiva da indústria, e da velocidade da inovação tecnológica, as informações perdem seu valor com mais facilidade, favorecendo modelos fragmentados. Por fim, os custos de transação, similarmente aos de coordenação, também têm caído vertiginosamente, na medida em que a especificidade dos ativos também tem caído.

A fim de se entender e comparar os casos Gradiente e Motorola, apresentar-se primeiramente uma breve descricao da indústria brasileira de aparelhos celulares, para posteriormente esses dois casos. Para descrever as cadeias da Gradiente e da Motorola utilizar-se-á o modelo da cadeia genérica apresentada na Figura 2.

Figura 2: Cadeia de Valor da Indústria de Aparelhos Celulares no Brasil

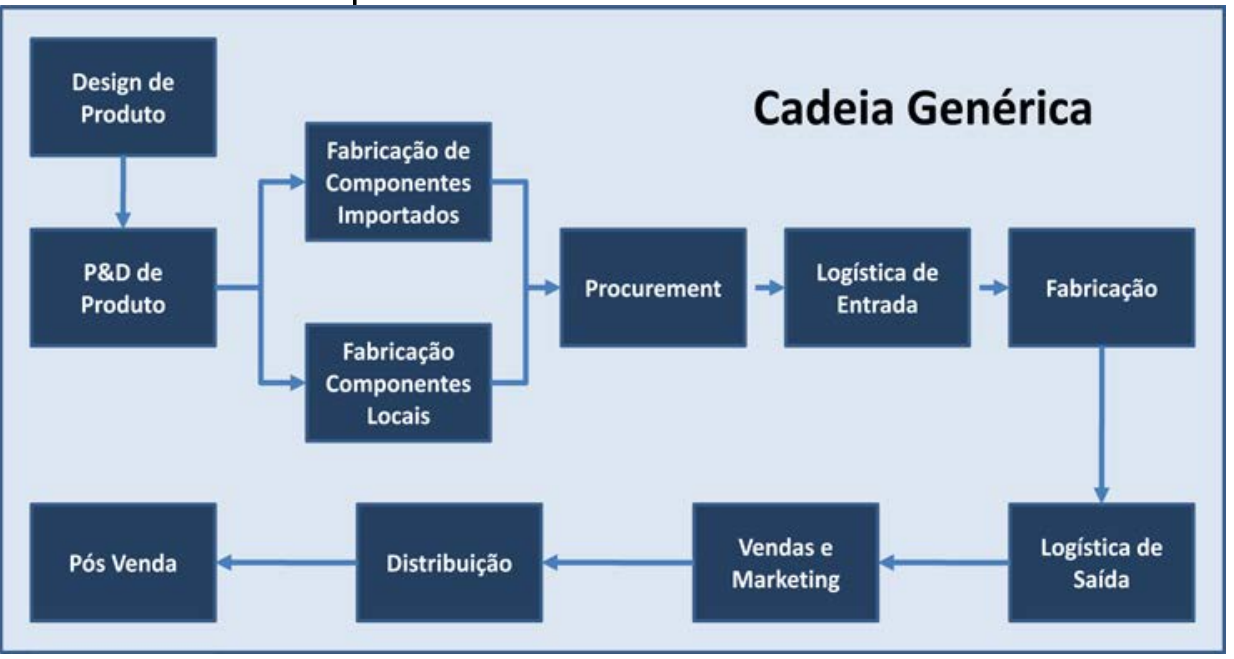

Fonte: Autores

\subsection{A Indústria Brasileira de Aparelhos Celulares}

O mercado brasileiro de telefonia cresceu a taxas elevadas nos últimos anos acompanhando a tendência que se observa no mundo todo. A evolução dos celulares foi muito rápida desde que o primeiro sistema entrou em operação em 1990. Em agosto de 2003, a quantidade de celulares ultrapassou a de acessos fixos em serviço. Em janeiro de 2007 o Brasil passou a ter mais de 100 milhões de celulares e atualmente possui quase 113 milhões de acessos móveis, configurando-se como o 50 mercado do mundo, atrás de China, USA, Índia e Rússia. Dados de janeiro de 2008 apontam que o país possui cerca de 120 
milhões de linhas telefônicas móveis ativas, o que chega perto da marca de $60 \%$ de penetração, ou seja, de 6 aparelhos para cada 10 habitantes (http://www.anatel.gov.br).

Uma das características sobre o mercado brasileiro de celulares é que, quase que a totalidade do que é consumido, é fabricado localmente. O modelo de negócio funciona a partir da importação da maior parte dos componentes já prontos. Localmente, de acordo com a lei do Processo Produtivo Básico (PPB), apenas as baterias e carregadores devem ser fornecidos. Toda parte de etiquetagem e embalagem segue a mesma regra. Portanto, do ponto de vista local todas as empresas presentes importam quase que a totalidade de seus componentes.

O início do serviço foi promovido pela então extinta Telebrás através de suas subsidiárias estaduais dentro do padrão analógico. No fim da década de 90 , com a privatização, grandes investimentos para expandir o serviço e melhorar a tecnologia foram feitos pelas empresas. A Figura 3 lista a presença dos principais fornecedores mundiais de aparelhos celulares, segundo dados do Teleco (www.teleco.com.br), e a localidade de suas instalações de manufatura no Brasil. Se for considerado que apenas a Nokia, Samsung, Motorola, LG e a SonyEricsson detinham mais de $83 \%$ do market share mundial pode-se perceber que praticamente $100 \%$ dos fabricantes estão presentes no Brasil fabricando localmente.

Figura 3: Fabricantes Presentes com Instalações de Manufatura no Brasil
\begin{tabular}{|l|l|}
\hline REGIÃO & FABRICANTES \\
\hline Zona Franca de Manaus & Nokia, Samsung, Siemens (BenQ), Gradiente, Vitelcom e Evadin \\
\hline São Paulo & Motorola, Sony Ericsson, LG, Samsung, Telemática (Venko) e Huawei \\
\hline
\end{tabular}

Fonte: www.teleco.com.br.

Após um período de consolidação no setor, hoje atuam principalmente no País: a Vivo, uma joint venture formada pelo grupo espanhol Telefonica Móvil e pelo grupo português, Portugal Telecom; a TIM do grupo Italiano Telecom Italia; a Claro do grupo mexicano America Móvil; a Oi pertencente a grupos empresariais locais (Construtora Andrade Gutierres e do GP Investimentos); a Brasil Telecom do Grupo Opportunity, e a Telemig/Amazonia Celular também do Grupo Opportunity. Recentemente a Vivo anunciou a compra da Telemig/Amazonia Celular em mais um movimento de consolidação do setor. Oi e BrT também trabalham com os órgãos reguladores para viabilizar uma fusão entre as duas empresas.

O perfil da base de usuários é descrito como predominantemente pré-pago, chegando à casa dos $80 \%$ aproximadamente de toda base de usuários, quando no ano de 2000 100\% da base era composta por planos pós pagos. O pré-pago foi um sucesso comercial incontestável pelos atributos de simplicidade, pela não necessidade de ficha cadastral na compra, possibilidade de controle dos gastos mensais, assim como por permitir que uma grande quantidade de usuários pudesse ter acesso ao serviço, mesmo com uma renda disponível baixa, como é o perfil da população no Brasil.

Como conseqüência desse modelo, ou seja, produtos orientados para baixa renda, o Brasil hoje tem uma das menores receitas médias por assinantes (em torno de $R \$ 30$ ) com uma taxa de utilização de 80 minutos por mês por usuário. Este ponto tem sido alvo de muitas críticas por parte dos investidores do setor, que têm tido grande dificuldade em obter retornos adequados para os altos investimentos feitos no Brasil.

Tabela 1 - Produção, Importação, Exportação e Venda de Aparelhos no Brasil

\begin{tabular}{lllll}
\hline Milhares de unidades & $\mathbf{2 0 0 3}$ & $\mathbf{2 0 0 4}$ & $\mathbf{2 0 0 5}$ & $\mathbf{2 0 0 6}$ \\
\hline Produção & 29.321 & 42.910 & 64.285 & 66.000 \\
Produção vendida & 27.336 & 41.696 & 63.367 & 66.000 \\
Exportação & 11.268 & 8.871 & 32.882 & 32.043 \\
Importação & 1.365 & 1.289 & 4.542 & 3.060 \\
Vendas no Brasil & 17.432 & 34.114 & 35.027 & 37.017 \\
\hline
\end{tabular}

Fonte: www.teleco.com.br.

A Tabela 1 traz as estimativas de vendas, produção, importação e exportação de produtos. Como pode ser observado, o Brasil é hoje uma plataforma regional de produção e exportação de aparelhos celulares. Em 
2006, 66 milhões de aparelhos foram produzidos num total mundial de pouco mais de 1 bilhão o que significa aproximadamente $6,5 \%$ do total.

\subsection{A Cadeia da Gradiente}

A Gradiente é uma empresa nacional com mais de 40 anos no mercado. Fundada em 1964, hoje conta com mais de 770 colaboradores distribuídos em seus escritórios administrativos, centros de distribuição (São Paulo), parque fabril em Manaus e um escritório na China. Atualmente a empresas possui duas áreas de negócio: Áudio \& Vídeo e Telecomunicações. Na primeira se concentra nas linhas de Mini System, Micro System, Som Portátil, Televisores, Displays de Plasma, DVD, Home Theater e DVDokê. Na segunda seu foco tem sido na fabricação de aparelhos celulares e acessórios. (www.gradiente.com.br)

Desde sua fundação, tem sido pioneira na introdução de produtos eletro-eletrônicos no Brasil. Alguns exemplos deste pioneirismo são a fabricação do primeiro amplificador transistorizado do país em 1965; em 1972 inaugurou sua primeira fábrica na Zona Franca de Manaus, constituindo-se numa das pioneiras na região e no Brasil em manufatura de produtos eletro-eletrônicos; lançamento do telefone no padrão brasileiro em 1978; lançamento do vídeo game Atari em 1983; primeiro CD player nacional em 1989; primeiro videogame nintendo em 1993, além de muito outros.

Na área de aparelhos celulares também teve papel de destaque na história da indústria no País. Em 1997 assinou uma joint venture com a Nokia para fabricação do primeiro telefone celular digital. A parceria durou até 2000 quando a Gradiente vendeu sua participação para a empresa Finlandesa por US\$ 415 milhões. Em 2003 firmou parceria com a francesa Sagem. Finalmente, em outubro de 2008, a empresa lançou um informe à imprensa comunicando sua parceria com a Brightstar no Brasil, o que marcou em menos de um ano a sua volta ao setor.

A Brightstar é atualmente o maior distribuidor Global de dispositivos móveis. Fundada em 1997, a empresa deve fechar o ano com mais de US\$ 4 bilhões de faturamento (www.brightstarcorp.com). Presente em todos os continentes, em mais de 49 países, a empresa distribui aproximadamente $5 \%$ de todos os celulares fabricados no mundo. Seus clientes dominam uma rede de distribuição de mais de 160.000 pontos de venda.

Ao contrario da Gradiente, a Brightstar possui uma presença global que Ihe dá uma posição mais fortalecida na interação com os desenvolvedores de produtos asiáticos. Antes dessa parceria, a Brightstar já havia iniciado atividades dessa natureza com a fabricante nacional chamada Evadin. Parceria esta que foi desfeita, dando lugar a esse novo arranjo com a Gradiente. Segundo o principal executivo da Brightstar no Brasil: "A parceria com a Gradiente representa um avanço no modelo de negócio, uma vez que cada parceiro está trazendo o melhor de sí e de suas capacidades, constituindo assim uma cadeia de valor mais fortalecida".

A parceria entre a Gradiente e a Brightstar no Brasil tem como característica principal um alto grau de desverticalização. A Figura 4 mostra a cadeia genérica descrita anteriormente e detalha, sob o ponto de vista de próprio ou terceirizado, cada um de seus elos.

Figura 4: Cadeia da Gradiente

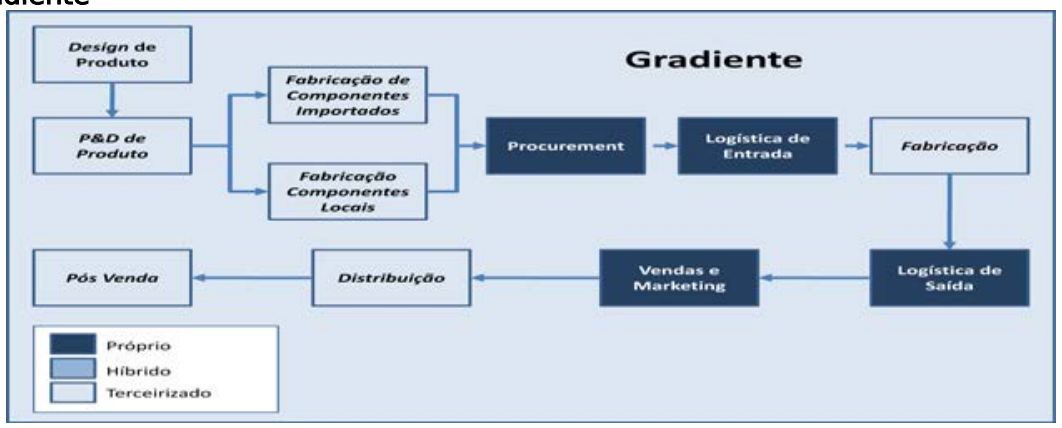

Fonte: Autores. 
Verticalização e competitividade na cadeia de suprimentos do setor de aparelhos celulares no Brasil: um estudo comparativo entre Motorola e Gradiente estudo.

A Figura 5 aponta o desempenho da Gradiente com base nas variáveis ambientais selecionadas no

Figura 5: Resumo da Adequação ao Padrão para o Caso 1 - Gradiente

\begin{tabular}{|l|c|}
\hline \multicolumn{1}{|c|}{ VARIÁVEIS DEPENDENTES DO AMBIENTE } & RESULTADOS \\
\cline { 2 - 2 } & Caso 1-Gradiente \\
\hline Custos como Estratégia Genérica & Forte \\
\hline Diferenciação & Baixa \\
\hline Enfoque & Sim \\
\hline Vantagens Competitivas em Recursos & Alta \\
\hline Relacionamento com Cadeia de Fornecedores & Boa \\
\hline Custos como Objetivo de Desempenho & Baixo \\
\hline Velocidade & Alta \\
\hline Flexibilidade & Grande \\
\hline Confiabilidade & Moderada \\
\hline Qualidade & Moderada \\
\hline Disruptivo & Sim \\
\hline
\end{tabular}

Fonte: Resultados da pesquisa.

\subsection{A Cadeia da Motorola}

A Motorola foi fundada em 1928 e foi pioneira na década de 30 nos rádios automotivos e redes de segurança pública. Mais recentemente, no ano de 1983, a empresa lançou o primeiro telefone celular do mundo e, em 1990, o primeiro padrão de televisão digital de alta definição do mundo (HDTV). Totalizando um faturamento global de US\$ 42,9 bilhões em 2006 a Motorola é atualmente uma das maiores e mais importantes empresas da indústria de comunicação sem fio. Suas principais linhas de produto compreendem soluções em mobilidade nas áreas de banda larga, sistemas integrados e redes sem fio.

Em 1992 a Motorola decidiu abrir suas instalações no Brasil e, em 1996, fez do País sua base industrial para atender o mercado sul americano. Desde então, a empresa tem investido largamente em unidades fabris e na contratação de mão-de-obra. O Brasil é hoje considerado como um dos quatro "de foco" no mundo, junto com a Rússia, a China e a índia. Atualmente, a empresa conta com mais de 7.500 empregados diretos contratados no País.

Até os dias atuais a empresa já investiu meio bilhão de dólares no País, grande parte foi destinada à construção do Campus Industrial e Tecnológico de Jaguariúna (SP), que, segundo a empresa, representa um novo conceito integrado de parque industrial com linhas de produção flexíveis. Também está lá instalado o Centro de Pesquisa e Desenvolvimento de Terminais Celulares e Infra-estrutura Celular, que abriga três centros de excelência mundiais nas áreas de Verificação de Integração de Software para Celulares, Messaging, e Aplicações e Serviços de Infra-estrutura. Estas iniciativas começaram em 1997, com o Programa de Desenvolvimento Tecnológico da Motorola, que já recebeu investimentos de mais de US\$ 250 milhões. A companhia tem atingido resultados significativos ao estabelecer parcerias com as principais universidades do País. Hoje, a companhia conta com um total de 900 engenheiros trabalhando na área de $P \& D$, na própria Motorola e instituições parceiras.

O complexo industrial da Motorola Brasil também é considerado grande centro exportador. A empresa é hoje a maior exportadora de bens de tecnologia da informação do País, totalizando mais de US\$ 5 bilhões desde o início das operações em 1997.

No Brasil, a Motorola está ainda fortemente presente na comercialização de soluções de rede, acesso à Internet e TV por banda larga, cable modems, sistemas automotivos, soluções de telemática, bem como o sistema de banda larga sem fio, além de desenvolver outras soluções para os mercados corporativo e de comunicação pessoal.

O modelo de negócio da Motorola é caracterizado por um alto grau de verticalização, principalmente se comparado ao da Gradiente. A Figura 6 mostra a cadeia genérica descrita anteriormente e detalha sob o ponto de vista de próprio ou terceirizado cada um de seus elos. 
Figura 6: Cadeia da Motorola

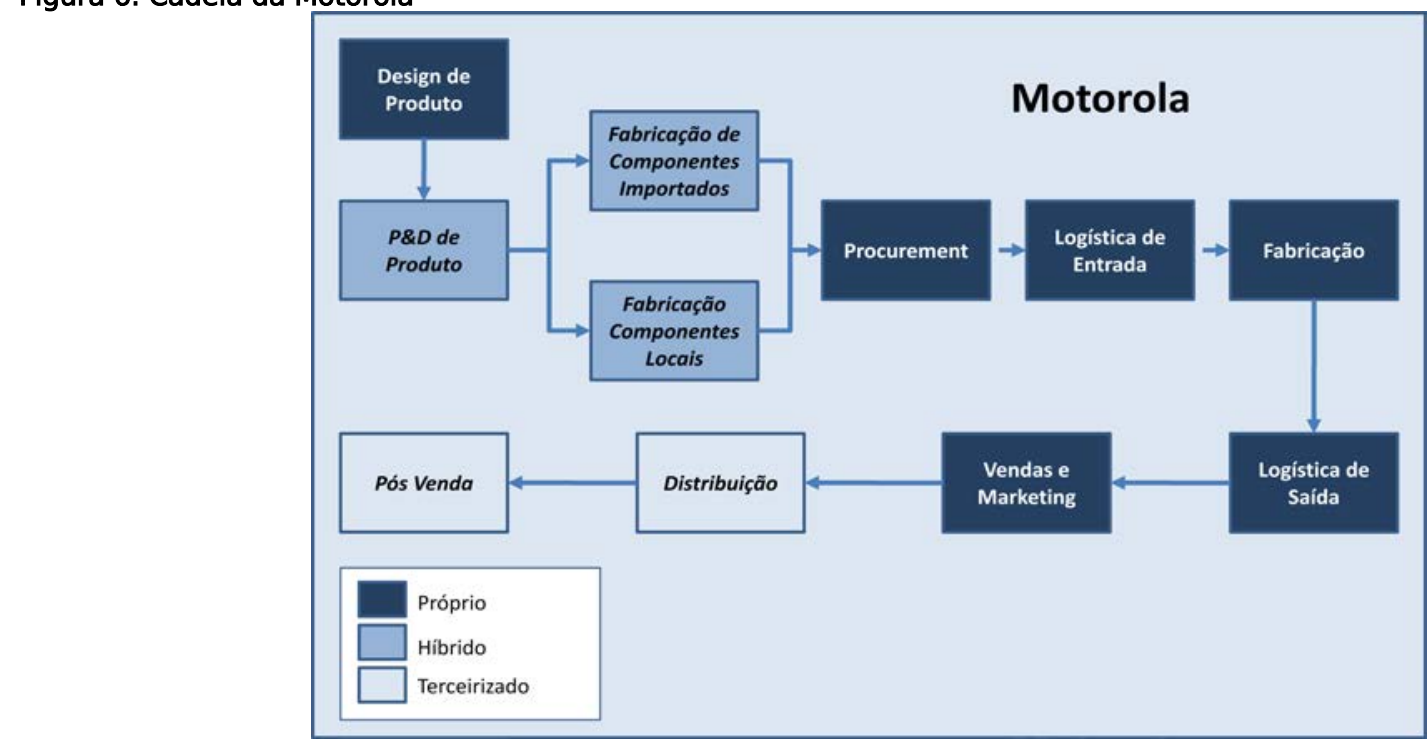

Fonte: Resultados da pesquisa

A Figura 7 resume as variáveis dependentes e seus respectivos padrões prognosticados e empíricos. Em seguida, se apresentará um detalhamento de tais constatações.

Figura 7: Resumo da Adequação ao Padrão para o Caso 2 - Motorola

Fonte: Resultados da pesquisa

\begin{tabular}{|l|l|}
\hline \multirow{2}{*}{ VARIÁVEIS DEPENDENTES DO AMBIENTE } & RESULTADOS \\
\cline { 2 - 2 } & Caso 2 - Motorola \\
\hline Custos como Estratégia Genérica & Moderada \\
\hline Diferenciação & Alta \\
\hline Enfoque & Não \\
\hline Vantagens Competitivas em Recursos & Baixa \\
\hline Relacionamento com Cadeia de Fornecedores & Atrativa \\
\hline Custos como Objetivo de Desempenho & Moderado \\
\hline Velocidade & Baixa \\
\hline Flexibilidade & Baixa \\
\hline Confiabilidade & Alta \\
\hline Qualidade & Alta \\
\hline Disruptivo & Não \\
\hline
\end{tabular}

\section{Resultados Comparados}

Os resultados mais interessantes mostram que a parceria Gradiente, por nascer desverticalizada e ter um alto grau de dependência de seus fornecedores, foi classificada como aquela que possui uma relação mais estável e saudável na cadeia de fornecedores. Por outro lado, os volumes de compra da Motorola atraem um número muito grande de empresas interessadas em vender seus insumos e serviços para a empresa, não importando o quão agressiva a mesma seja na gestão do relacionamento. É complicado obter lucro sendo fornecedor da Motorola, em função de seu alto poder de barganha junto a fornecedores.

No caso da parceria Gradiente, a instabilidade potencial que poderia existir caso algum elo da cadeia se desestabilizasse, provocando um colapso de toda cadeia. De forma geral a estrutura desverticalizada é vista como mais arriscada. Os benefícios provenientes de uma estrutura flexível não são suficientes para compensar a sensação de vulnerabilidade, que decorre de um modelo de negócio fragmentado. Acredita-se que exista um fator paradigmático em questão: de forma geral, as pessoas têm dificuldades de reconhecer o mérito e potencial de idéias novas até que seu sucesso seja consolidado.

Há um nível maior de confiança no modelo verticalizado quando o tema é cadeia de fornecimento. De acordo com o Gerente Geral da Brightstar no Brasil, não importa muito quão agressiva seja a postura da Motorola frente a seus fornecedores, pois, para cada um que possa vir a perder dinheiro, existirá um fila de muitos outros novos fornecedores tentando aproveitar as oportunidades de negócio gigantescas 
apresentadas pela empresa. Apesar desses fatos, um indicador específico chama a atenção, o nível de atrito na cadeia de fornecedores sendo menor para a Gradiente do que para a Motorola. Entende-se também, que ele não se consubstanciará em vantagem competitiva (Porter, 1980), caso a relação de poder na cadeia não seja equilibrada, ou seja, que uma das partes assuma um papel tão preponderante que passará a ditar as regras dentro da cadeia de forma excessivamente arbitrária.

No que diz respeito aos objetivos de desempenho os entrevistados classificaram em geral a Gradiente como mais apta em velocidade e flexibilidade, moderada em custos e inferior em qualidade e confiabilidade. No caso da Motorola os resultados foram de custos, qualidade e confiabilidade altos e velocidade e flexibilidade extremamente baixos.

Os custos (ou preço) foram considerados por unanimidade, pelos entrevistados, o fator primordial ganhador de pedido. Em seguida a velocidade e a flexibilidade foram classificadas como ganhadoras de pedido. A qualidade, surpreendentemente, foi classificada como qualificadora no processo de compras por cinco entrevistados, sendo que apenas um considerou-a ganhadora de pedidos. A confiabilidade teve três opiniões favoráveis à ganhadora de pedidos e três à qualificadora.

No que diz respeito à classificação, os negócios verticalizados parecem ser melhores em confiabilidade, seguidos de custos e depois de qualidade. Sendo mal avaliados em termos de velocidade e flexibilidade. No caso da parceria Gradiente, os pontos que mereceram destaque foram exatamente os inversos, ou seja, a flexibilidade em primeiro lugar e a velocidade em seguida. Os custos aparecem como sendo um objetivo reconhecido (62\%), mas menos do que no caso da Motorola, aonde o índice chegou a $87 \%$.

Em termos de recursos (Barney, 1986), a Motorola é mais percebida pela sua marca consolidada e pela capacidade em inovação de produtos (objetivo específico seis). Por outro lado, a parceria Gradiente possui maior flexibilidade, velocidade e custo baixo. Com relação ao relacionamento na cadeia (Fine, 1999) parece ser melhor da Motorola do que o da parceria Gradiente, acredita-se que pelo fato de se ter maior poder de barganha e por isso controlar melhor toda cadeia.

Analisando os dados da pesquisa à luz da teoria de Slack (2002), nota-se que por um lado a Motorola se sai bem no objetivo de custo, por outro lado a Gradiente obteve um reconhecimento significativo quanto à sua capacidade de trabalhar com custos baixos, ao mesmo tempo que foi unânime nos outros dois objetivos de desempenho, a flexibilidade e a velocidade. Por fim apenas o negócio da parceria Gradiente foi considerado disruptivo (Christensen, 2003).

\section{Considerações Finais e conclusão}

Este trabalho tem a virtude de acrescentar conhecimento específico à área da indústria de aparelhos celulares, que é ainda pouco estudada dentro da administração. Muitos estudos sobre plataforma asiática de produção de insumos e desenvolvimento de produto podem ser encontrados. Entretanto, análises mais aprofundadas dos impactos que as transformações na cadeia e na indústria podem trazer para o campo de batalha da concorrência e para os concorrentes, são muito difíceis de serem encontradas.

Com relação ao momento atual da indústria de telefonia, as principais evidências (Figura 8) fornecem indícios de que esse mercado vive um momento de amadurecimento, e, até mesmo, de disruptura ( 2004).

Figura 8: Momento Atual da Indústria de Aparelhos Celulares

Evidências um crescimento vegetativo abaixo de dois dígitos (22\% em 2006, 16\% em 2007 e projeções de mercado indicando para $7 \%$ em 2008);

2. penetração total de mercado perto de ser atingida. Mercado caminha para substituição e reposição;

3. preço médio em trajetória de queda já há muitos anos, apesar da concomitante melhoria dos produtos em termos de funcionalidade, capacidade e design (Motorola caiu de US\$299 em 1998 para US\$121 em 2007);

4. projeções de volume de vendas, associadas com projeções de preços médio, indicando perspectiva de queda do faturamento total da indústria nos próximos anos;

5. difusão da tecnologia de desenvolvimento de produto. Atualmente, a capacitação para se desenvolver hardware e software de celulares foi massificada na Ásia;

6. concentração de empresas na indústria. As 5 maiores, que representavam $75 \%$ do total do mercado em 2005, devem encerrar 2007 com 83\%;

7. surgimento de empresas de nicho, tais como RIM, HTC e SonyEricsson;

Fonte: elaborado pelos autores 
No que tange a procurar indícios sobre as forças que atuavam no mercado favorecendo, ou desfavorecendo a verticalização, tem-se que há indícios (Figura 9) que apontam a tendência de favorecimento a estruturas desverticalizadas.

Figura 9: Forças que apontam o favorecimento a estruturas desverticalizadas

\section{Evidências}

1. arquitetura do produto modular no que se refere ao hardware. Fornecedores da cadeia espalhados em diferentes empresas. Aparentemente, a modularidade vem aumentando. Em termos de software, a tendência parece ser a mesma (BALDWIN \& CLARK, 1997);

2. escala de produção possível de ser comprada no mercado a preços competitivos, assim como projetos prontos para venda de produtos desenvolvidos (PORTER, Competitive Strategy, 1980);

3. especificidade dos ativos muito baixa, caminhando para ficar ainda menores. Possíveis causas poderiam ser uma crescente modularização do produto e a fragmentação da cadeia (WILLIAMSON, 1985);

4. custos de transação decrescendo, na medida em que as tecnologias da informação facilitam a comunicação e a coordenação das empresas (WILLIAMSON, 1985);

5. custos de agência crescentes nas estruturas verticalizadas (WILLIAMSON, 1985);

6. complexidade dimensional crescendo, como conseqüência das diferenças regionais dos mercados e dos segmentos de produto necessários para atender a todos os gostos dos consumidores (FINE, 1999);

7. alta inflexibilidade organizacional das empresas verticalizadas e tradicionais (FINE, 1999):

8. incrível velocidade de renovação tecnológica e diminuição do ciclo de vida dos produtos (FINE, 1999);

9. baixo aproveitamento pelos clientes de todas as funcionalidades disponíveis e incorporadas nos aparelhos (CHRISTENSEN, O Crescimento pela Inovação, 2003)

Fonte: elaborado pelos autores

Em suma, a um mercado amadurecido, cujas variáveis favorecem modelos desverticalizados, numa indústria com baixas barreiras de entrada e compradores poderosos fomentando o surgimento de novos fornecedores, juntam-se fortes indícios que podem explicar a melhor ou pior aderência de diferentes modelos de negócio na indústria. Ou seja, modelos de negócio desverticalizados e estratégias em operações baseadas em custos competitivos, baixos ciclos de introdução de produto, flexibilidade organizacional, parecem se adequar mais a mercados maduros com tendência a disruptura, com baixas barreiras de entrada e com poderosos compradores fomentando a entrada de novos fornecedores.

As limitações a este trabalho decorrem, principalmente, do próprio escopo de estudo estabelecido. Certamente, a adição de outros casos poderia aumentar imensamente a validade das conclusões aqui descritas. Neste sentido, como sugestões a estudos futuros, apontam-se alguns pontos específicos: (i) os caminhos da modularidade na indústria - relação entre hardware e software; (ii) a cadeia de valor merece ser entendida com mais profundidade; as novas tecnologias disruptivas; (iii) uma averiguação sobre a questão dos custos efetivos; (iv) a especificidade dos ativos; e ( $v$ ) outros casos poderiam ser adicionados ao estudo como forma de se gerar mais replicações teóricas ou literais.

\section{Referências}

Baldwin, C. Y. \& Clark, C. B. (1997). Managing in an age of modularity. Harvard Business Review, Cambridge, September-October, pp. 84-93.

Bardin, L. (1977). Análise de conteúdo. Lisboa: Edições 70.

Barney, J. (1986). Firm resources and sustained competitive advantage. Journal of Management, v.17, No.1, pp. 99-120. doi:10.1177/014920639101700108

Barney, J. (1986). Strategic factor markets: expectations, luck, and business strategy. Management Science, v. 32, No. 10, pp. 1231-1241. doi:10.1287/mnsc.32.10.1231

Besanko, D., Dranove, D., Shanley, M. \& Schaefer, S. (2004). Economics of strategy. United States: John Wiley \& Sons.

Cañez, L.; Probert, D. \& Plattz, K. (2000). Developing a framework for make-or-buy decision. International Journal of Operations and Production Management. v. 20, No. 11, pp. 1313-1331. doi:10.1108/01443570010348271

Christensen, C. (2003). O crescimento pela inovação. Rio de Janeiro: Elsevier, 2003.

Collis, J. \& Hussey, R. (2003). Pesquisa em administração. Porto Alegre: Bookman. 
Di Serio, L. e Sampaio, M. (2001). Projeto de cadeia de suprimento: uma visao dinâmica da decisão de fazer versus comprar. Revista de Administração de Empresas. v. 41, n.1, pp. 54-66.

Easterby-Smith, M.; Thorpe, R. \& Lowe, A. (1991). Management research: an Introduction. London: Sage.

Fine, C. (2000). Clockspeed-based strategies for supply chain design. Production and Operations Management, v. 9, No. 3, pp. 213-221. doi:10.1111/j.1937-5956.2000.tb00134.x

Fine, C. H. (1999). Mercados em evolução contínua: conquistando vantagem competitiva num mundo em constante mutação. Rio de Janeiro: Campus.

Guedes, L. (2004). Contribuições ao estudo de um sistema de apoio à decisão - tópicos de alinhamento estratégico da tecnologia da informação e um estudo de caso no setor de medicina diagnóstica. São Paulo: EAESP/FGV.

Hamel, G. \& Prahalad, C. (1994). Competing for the future. Boston: Harvard Business School Press.

Hayes, R. H. \& Upton, D. M. (1998). Operations based strategy. California Management Review, v. 40, No. 4, pp. 8-25.

Herriott, R. E. \& Firestone, W. A. (1983). Multisided qualitative policy research: optimizing description and generalizability. Educational Researcher, 12, pp.14-19.

Porter, M. (1980). Competitive strategy. New York: The Free Press.

Quinn, J. \& Hilmer, F. (1994). Make versus buy: strategic outsourcing. Sloan Management Review, Summer, pp. 43-55.

Normann, R. (1970). A personal quest for methodology. Stockholm: Scandinavian Institutes for Administrative Research.

Rebelo, M. L. (2004). Estratégia competitiva de uma empresa fabricante de equipamentos de transportes. São Paulo: Fundação Getúlio Vargas - Escola de Administração de Empresas de São Paulo.

Scapens, R. W. (1990). Researching management accounting practice: the role of case study methods. British Accounting Review, pp. 259-810. doi:10.1016/0890-8389(90)90008-6

Skinner, W. (1969). Manufacturing - missing link in corporate strategy. Harvard Business Review. May-June, pp.136-145.

Slack, N. (2002). Vantagem competitiva em manufatura. São Paulo: Atlas.

Van Maanen, J. (1988). Tales of the field: on writing ethnography. Chicago: University of Chicago Press.

Venkatesan, R. (1992). Strategic sourcing: to make or not to make. Harvard Business Review. v. 70, No.8, pp. 98-107.

Wheelwright, S.C. (1984). Manufacturing strategy: defining the missing link. Strategic Management Journal. v. 5, pp. 77-91. doi:10.1002/smj. 4250050106

Williamson, O. (1985). The economic institutions of capitalism. New York: Free Press.

Yin, R. K. (2005). Estudo de caso: planejamento e métodos. Porto Alegre: Bookman. 